\title{
Desastres, desarrollo y género
}

Los desastres tienen un impacto adverso sobre el desarrollo de un país o una región. Se estima que por los daños ocasionados por el huracán Mitch en Centroamérica los países más afectados (Honduras y Nicaragua) atrasaron su desarrollo en 30 años: el dinero que podría haberse dedicado a educación, salud y vivienda se tuvo que invertir en atender la emergencia y la recuperación posdesastre. En El Salvador, los desastres debidos al Mitch y a los terremotos de 2001 dejaron 2,236.6 millones de dólares en pérdidas económicas, 1,674,550 personas afectadas y 1,634 muertos.

En esta línea, los modelos de desarrollo no sostenible - como el que ha aplicado El Salvador en las últimas décadas- profundizan el impacto que los fenómenos naturales o los causados por la actividad humana ocasionan cuando se convierten en desastres, provocando así pérdida de vidas e infraestructura (puentes, carreteras, hospitales, viviendas y escuelas, entre otros) y disrupción de la actividad económica y del tejido social. Pérdida de vidas que debe entenderse en sentido amplio, es decir, no solo incluyendo a las humanas, sino también la de ecosistemas completos (animales y plantas).

Esta relación entre desastres y modelos de desarrollo queda en evidencia cuando se observa que los países con índice de desarrollo humano alto sufren menos el impacto de los desastres que los países de desarrollo humano medio (como El Salvador) y bajo. Estudios del PNUD indican que El Salvador tiene un promedio de 103.52 muertos al año debido a terremotos, ciclones tropicales e inundaciones, y 17.25 muertos por desastres por cada millón de habitantes. Mientras que naciones como Noruega y Holanda tienen menos de 0.01 muertos por millón de habitantes; Estados Unidos y Japón, países con un alto número de desastres anuales, se encuentran por debajo de los 5 muertos por cada millón de habitantes. Lo anterior indica que si el país dedicara sus recursos a cumplir los Objetivos de Desarrollo del Milenio, reduciría de manera significativa y sostenible el impacto de los desastres.

Otro ejemplo de esta relación desastres-desarrollo se encuentra al comparar los terremotos de Nicaragua en 1972 (magnitud 7.2 grados Richter) y el de San Fernando, California, en 1971 (magnitud 6.6). Aunque de magnitud parecida, estos movimientos sísmicos produjeron 10,000 y 65 muertos, respectivamente, según la base internacional de datos de desastres EM-DAT, desarrollada por el Centro de Investigación sobre la Epidemiología de los Desastres con apoyo de la Universidad Católica de Lovaina (Bélgica). Más 
aún: según datos del Banco Mundial del año 2001, el 95\% de las muertes relacionadas con desastres ocurren entre el $66 \%$ de la población del mundo que vive en los países pobres.

Todo esto indica que las estrategias para hacer frente a los desastres deben enfocarse primordialmente en la reducción de la vulnerabilidad socioeconómica, y ello pasa por cambiar el modelo de desarrollo. Esto se puede analizar a niveles nacional y global. En el primer nivel, los datos muestran que el modelo neoliberal adoptado por El Salvador en los últimos 20 años ha aumentado la pobreza y la exclusión social, y ha ampliado la brecha en los ingresos entre ricos y pobres. El país, pues, se ha vuelto muy vulnerable por el incremento de la exposición física (más personas viviendo en zonas de riesgo y en viviendas precarias); además, ha aumentado la fragilidad ambiental y disminuido la capacidad de la población para recuperarse después de un desastre (la resiliencia). Un estudio de indicadores de gestión de riesgos del BID indica que, para 2000, de doce países de Latinoamérica y el Caribe evaluados, El Salvador ocupaba la segunda posición de los más altos índices de vulnerabilidad prevalente (IVP) (sólo por debajo de Jamaica y seguido por Guatemala y República Dominicana). En esta situación de alta vulnerabilidad, y estando ubicado en una zona de múltiples amenazas naturales, El Salvador será inviable en el futuro de no abordarse en serio el camino hacia un desarrollo sostenible.

La gestión del riesgo parte del hecho de que los desastres se construyen socialmente $y$ que estos se pueden superar poniendo el énfasis más en sus causas (reducción de las vulnerabilidades) que en sus efectos (atender la emergencia y la recuperación).
A nivel global se observa que el modelo neoliberal ha producido degradación ambiental, cambio climático, incremento de las desigualdades sociales, acelerada e intensiva urbanización, presión de la población por acceso a recursos como alimentos, agua y energía... Así, la globalización económica se ha convertido en un factor poderoso que ha incrementado la probabilidad de destrucción después de un terremoto, un ciclón, una sequía, etc. Además, la interdependencia mundial en torno al suministro de energía (petróleo y otros combustibles), los mercados financieros y las redes de telecomunicación puede abonar a la problemática social y económica de los países en caso de ocurrir un desastre. Un ejemplo: el cambio de rumbo del huracán Ida hacia México hizo que el precio del barril aumentara, complicando de esta manera la recuperación económica de los países que se vieron afectados por el fenómeno natural.

En este contexto, ECA dedica esta edición al tema de la gestión de riesgos con equidad de género. Tema en el que dos líneas de estudio con desigual desarrollo (hay mucho trabajo en gestión de riesgos y poco en equidad de género) se juntan para contribuir al logro de los Objetivos 3 y 7 de Desarrollo del Milenio: respectivamente, promover la igualdad de género y el empoderamiento de la mujer, y asegurar la sostenibilidad ambiental. En este sentido, para abordar el tema de la gestión de riesgos se parte de nuestro historial de desastres, mientras que el tema de la equidad de género se considera desde el reconocimiento de que los desastres impactan de manera diferenciada a hombres y mujeres. 
Las herramientas metodológicas de la teoría de género - aún en construcción- han transitado desde el enfoque de Mujer en Desarrollo, pasando por el enfoque de Género en el Desarrollo, hasta llegar al enfoque actual de Género-inclusivo, que tiene una visión de equidad entre mujeres y hombres con una modalidad operativa hacia cada uno. Este proceso de construcción de la teoría de género ha generado dos conceptos fundamentales. El primero es el empoderamiento, que se caracteriza por enfatizar que el desarrollo no beneficia a todas las personas por igual y rechaza la idea de que las mujeres deben integrarse en las acciones o iniciativas de desarrollo sin una perspectiva propia. El segundo, la transversalización de género, que implica incorporar el enfoque de género en los distintos componentes de una institución, política, programa o proyecto, de tal forma que hombres y mujeres trabajen juntos para mejorar sus condiciones. El desarrollo del enfoque de la gestión de riesgos con equidad de género representa no sólo un reto intelectual, sino también una gran oportunidad para aportar a la construcción de un país más justo, incluyente y seguro.

La historia de desastres de El Salvador indica que sus principales amenazas son los terremotos, los deslizamientos de tierra, las tormentas (inundaciones y desbordamientos de ríos) y las epidemias. Estas últimas han sido más frecuentes y severas a partir del año 2003. El cólera, rotavirus, diarreas, dengue, bronconeumonías, tuberculosis, neumonías, gripes y conjuntivitis son epidemias ahora más comunes y reincidentes a consecuencia directa de la contaminación ambiental, principalmente del aire y del agua. $\mathrm{Si}$ se aplica el modelo conceptual de que el riesgo de desastre es producto de la exposición física multiplicada por las vulnerabilidades, y se considera que la exposición física depende de la severidad y frecuencia de la amenaza y del elemento en riesgo (población, vivienda, etc.), nuestra historia de desastres nos indica que, por el lado de la exposición física, debe ponerse más atención a los terremotos y a la contaminación ambiental como amenazas; mientras que por el lado de las vulnerabilidades debe fijarse la atención en las socioeconómicas, lo que implica adoptar un modelo de desarrollo sostenible antes que optar por la simple construcción de obras de mitigación.

En el caso de los terremotos, a partir del examen de la base de desastres EM-DAT, se concluye que el factor de vulnerabilidad física que más incide en el impacto del desastre es el crecimiento urbano, y que los elementos en riesgo más afectados son la población y la vivienda. Esto quedó en evidencia en el país durante los terremotos de 2001, cuando 163,866 viviendas (11.68\% del total) colapsaron y alrededor de 107,787 (7.68\%) quedaron seriamente dañadas. En esta línea, es necesario apostar por las investigaciones sobre materiales para la construcción de viviendas sismorresistentes que reduzcan la vulnerabilidad física frente a sismos; así como también por la elaboración de planes de ordenamiento territorial como instrumentos clave para reducir la pobreza. Entendiendo dicho ordenamiento como el desarrollo equilibrado del conjunto de regiones que componen el territorio, lo que implica, por un lado, el establecimiento de redes de comunicación que conecten todas sus partes; y, por otro, la creación y aplicación de un sistema de ayudas económicas y sociales que compensen las desigualdades de desarrollo. 
Así, la gestión de riesgos debe entenderse como la administración y caracterización adecuadas de las amenazas, vulnerabilidades (físicas, sociales, políticas y económicas) y elementos en riesgo (personas, infraestructura y servicios) de un territorio dado, a fin de reducir los efectos de un probable desastre y, a la vez, elaborar planes de emergencia encaminados al restablecimiento ágil del tejido social y económico del territorio en consideración. La gestión del riesgo así entendida parte del hecho de que los desastres se construyen socialmente y que estos se pueden superar poniendo el énfasis más en sus causas (reducción de las vulnerabilidades) que en sus efectos (atender la emergencia y la recuperación). Esta gestión será efectiva si en sus etapas tradicionales de caracterización, evaluación y tratamiento de los riesgos recurre a la participación ciudadana y la transversalización de género. Esto último pasa por reconocer que el género le da forma al mundo en que ocurren los eventos naturales o humanos, y que las diferencias de género aparecen en las condiciones predesastre, en la preparación de la emergencia, durante el desastre, en la acción voluntaria, en la comunicación de la emergencia, la división del trabajo, el estrés postraumático y en la forma de afrontar la emergencia.

En general, se habla ahora de vulnerabilidad de género debido a que históricamente las mujeres son más vulnerables ante un desastre por las condiciones de marginación social, pobreza, inseguridad económica, sobrecarga de responsabilidades de cuidado a personas y falta de poder social y voz política que padecen. Los impactos económicos de los desastres ocasionan, tanto para hombres como para mujeres, destrucción de tierras, hogares, cosechas, ganado, entre otros. También los empleos se pierden cuando los hogares y los lugares de trabajo se destruyen, los mercados colapsan y las redes de transporte fallan. Pero, por ejemplo, el fuerte vínculo de la mujer con las responsabilidades del cuidado del hogar después de ocurrido un desastre la inmoviliza y le imposibilita migrar fuera del área impactada para obtener un salario que le permita recuperarse económicamente. Algo diferente sucede con el hombre, que con facilidad emigra para conseguir un empleo estable (fenómeno conocido en los estudios de desastres como flight of men). Esto hace que la recuperación económica posdesastre de la mujer sea más lenta que la del hombre. Además, las mujeres son las que asumen la responsabilidad de buscar asistencia de socorro después de ocurrido un desastre. Ello implica, muchas veces, largos períodos de espera, papeleos y cargar con el estigma de que son ellas las que necesitan ayuda. Este trabajo de búsqueda de auxilio entra en conflicto con la recuperación del trabajo del hogar y con las responsabilidades del trabajo pagado, lo que dificulta que se recupere la normalidad de vida. Es claro, entonces, que hay mucho por hacer en el conocimiento de los impactos debido a género; una de las debilidades del país está precisamente en la investigación y el análisis de desastres desde este enfoque. Es hora de empezar a saldar esa deuda. 